\title{
Multiple sclerosis in south Cambridgeshire: incidence and prevalence based on a district register
}

\author{
N Robertson, J Deans, M Fraser, D A S Compston
}

\begin{abstract}
Study objective - To establish an updated prevalence and incidence figure for multiple sclerosis on 1 July 1993, to determine the fate of the 374 patients prevalent in 1990 , and to establish the origin of incident patients.
\end{abstract}

Design - Case ascertainment was from several sources including departmental records, local branches of the Multiple Sclerosis Society, general practitioners, nursing homes, and residential facilities for the disabled. Data collection was by personal interview using a standardised questionnaire and by retrospective analysis of departmental case notes. A prospective incidence register of newly diagnosed patents was maintained from 1990.

Setting - The Cambridge Health District of East Anglia covering 340910 hectares in area and a population of 290700 .

Patients - Altogether 441 patients prevalent on 1 July 1993 were identified, of whom 328 were contacted so that clinical data could be collected. Seventy patients $(16 \%)$ either declined to take part or access was denied by their general practitioner; $8(2 \%)$ had died; and $35(8 \%)$ were too ill or failed to respond to several requests for contact.

Main results - A comprehensive re-evaluation of the south Cambridgeshire multiple sclerosis register revealed a prevalence of $441 / 290700$ population (152/ $10^{5}$ ) for all disease classifications on $1 \mathrm{July}$ 1993. This represented an increase of $18 \%$ from 1990 and was a result of 138 additions and 71 deletions from the original list of 374 patients. The sex ratio of prevalent patients was $2.6 \mathrm{~F}: \mathrm{M}$, the mean age at disease onset was 31.7 years, and the mean age was 49 years. Mortality for 1990-93 was $3 \cdot 3 / 10^{5} /$ year and prospective maintenance of an incidence register recorded 96 new diagnoses for all classifications of multiple sclerosis over the five year period 1990-94 (6.6/10 /year).

Conclusions - The increase in prevalence mainly resulted from improved case ascertainment identifying a further 58 patients who had been prevalent in 1990 . Comparisons with other serial studies within the United Kingdom show similarities in proportional increase with successive studies indicating that serial survey may in part account for the ob- served latitudinal gradient within the United Kingdom. However, the observed prevalence $\left(152 / 10^{5}\right)$ in this second survey still falls short of the figure estimated from incidence and mortality data $\left(186 / 10^{5}\right)$.

( $($ Epidemiol Community Health 1996:50:274-279)

The relatively few epidemiological studies of multiple sclerosis which have maintained large population based registers and provide the opportunity for serial measurements of prevalence have been especially influential in generating hypotheses for causation of the disease. ${ }^{1-3}$ In particular, studies in north east Scotland recorded the highest known prevalence and spawned the observation of a latitudinal gradient for the disease. The existence of this gradient seems indisputable; however, despite extensive investigation no environmental agent which explains this phenomenon has been incriminated. With increasing evidence of a genetic contribution to disease aetiology, it is of considerable importance to establish whether this gradient exists between or within genetically homogenous populations, or alternatively is an artefact of enhanced ascertainment resulting from serial estimations of prevalence in defined areas.

The Cambridgeshire register of patients with multiple sclerosis was established in 1989 and presented prevalence data from the Cambridge Health District on July $11990,{ }^{4}$ demonstrating a combined disease prevalence of $130 / 10^{5}$ for suspected and probable/definite multiple sclerosis in this previously unsurveyed population. The register has since been maintained and incidence data have been collected prospectively since January 1990. A comprehensive re-evaluation of the population was undertaken on July 11993 in order to identify patients missed in the initial study, to establish a new prevalence rate, and to report five year incidence and mortality data for the period 1990-94. These statistics have allowed us to assess the extent to which epidemiological surveys underestimate the prevalence rate expected from incidence and mortality data.

\section{STUDY AREA}

Cambridgeshire is a land locked county, lying in a predominantly rural region within a recognised area of high disease prevalence between latitudes 50 and 52 degrees north of the equator, and covering an area of 340910 
hectares. Its predominant geographical feature is of flat terrain, with extensive fenlands to the north and east of the county. It is separated into six county districts and is served by four health authorities, the largest of which is the Cambridgeshire health district, which provides care for the southern half of the county. Within its boundaries lie two large population centres - the university city of Cambridge and the city of Ely. Neurological services are provided by one regional centre based at Addenbrooke's Hospital in Cambridge, and outpatient neurological services are also maintained by consultant staff from Cambridge working at four district general hospitals surrounding the study area. All inpatient investigation is performed at a single regional neurology unit in Cambridge and the department holds records for all patients seen since 1965, irrespective of domicile. The area is served by 350 general practitioners from 121 main surgeries and 30 branch surgeries, although some patients are registered with general practitioners outside the county boundaries. Population figures for the study area are published by the Cambridgeshire County Council Population Research Group, and report a 1991 mid-year estimate of $290700 .^{5}$

\section{Methods}

A preliminary register was established based on the patients originally identified in the 1990 survey and this has been maintained ever since. In addition, all 32301 sets of departmental notes were re-examined in order to identify any individuals omitted from the first 1990 list. This preliminary register was entered into the family health services authority computer to identify those patients who were alive, resident in the study area, and currently registered with a general practitioner.

Three additional sources were used to identify patients with suspected or confirmed multiple sclerosis. The aims of the study were explained to all general practitioners within the Cambridge, Huntingdon, and Peterborough health districts and adjoining areas, and a record of patients believed to be registered with their practice on July 11990 was provided. General practitioners were asked for any amendments to identification details and permission to contact incident patients with suspected or confirmed multiple sclerosis who had not appeared on the original register. $\mathrm{Re}$ minders were sent at four monthly intervals to practitioners who did not respond. Secondly, all local branch secretaries of the Multiple Sclerosis Society of Great Britain and Northern Ireland were asked to provide membership lists. Thirdly, all nursing homes and facilities for the disabled were contacted to identify additional patients.

The methodology of case ascertainment closely followed the original study, ${ }^{4}$ but on this occasion no attempt was made to identify patients from the hospital inpatient database since no unique identifications had occurred from this source in 1990 and all neurological outpatient notes and inpatient discharge sum- maries had been scrutinised prospectively from that time.

Attempts were made to contact all patients on the provisional register in order to collect clinical data and confirm residence within the study area. Where this was not possible, hospital and/or primary case notes were reviewed. Clinical classifications used the criteria of Poser et $a l^{6}$ and Allison and Millar ${ }^{7}$ so that comparisons could be made with earlier studies. For the Poser criteria, as in the original study, clinically definite multiple sclerosis (CDMS), laboratory supported definite multiple sclerosis (LSDMS), clinically probable multiple sclerosis (CPMS); and laboratory supported probable multiple sclerosis (LSPMS) were collectively categorised as multiple sclerosis (MS); these were distinguished from cases with suspected multiple sclerosis and those with other neurological diseases. Age and sex specific prevalence was calculated as well as standardised prevalence rates, based on the 1961 population census of Northern Ireland. ${ }^{4}$ Results are compared with other second surveys, particularly those performed in the north east of Scotland, ${ }^{8-10}$ Northern Ireland, ${ }^{711}$ and south east Wales. ${ }^{12}$

The status of all 374 patients prevalent in 1990 was re-evaluated. Most were still prevalent, but some had died or moved out of the study area. In a few the diagnosis of multiple sclerosis had been refuted and a number of patients with suspected multiple sclerosis had changed diagnostic category. In addition, all new diagnoses of multiple sclerosis made by Cambridge based neurologists were used to derive incidence figures over a five year period from January 1990 to December 1994, after categorising patients according on whether they were newly diagnosed, had moved into the study area, or were prevalent in July 1990 but not ascertained.

\section{Results}

The provisional register contained 662 patients from all sources. Every general practice responded to the request to participate in the study; but two elected not to provide lists of patients because of concerns regarding confidentiality. A total of 194 patients on the provisional register had either died, moved away from the area, were duplicate referrals, or an alternative diagnosis had been established, and these were all excluded. After further clinical evaluation based on a personal interview or review of existing medical records, the diagnosis could not be confirmed in a further 27 individuals. The final register therefore comprised 441 patients with multiple sclerosis who were alive and prevalent within the study area on the 1 July 1993. The largest source of ascertainment was from departmental notes, which identified 368 (83\%) of the prevalent patients. General practitioner referrals accounted for $225(51 \%)$, the Multiple Sclerosis Society for $8(2 \%)$, and nursing homes 13 (3\%). Of the 255 patients notified from a single source, $199(45 \%)$ were derived from departmental notes, $53(12 \%)$ from general 
Table 1 Diagnostic classification of prevalent patients

\begin{tabular}{|c|c|c|c|c|}
\hline & No & $(\%)$ & Prevalence & $(95 \% C I)$ \\
\hline \multicolumn{5}{|l|}{ Poser classification } \\
\hline Clinically definite & 281 & 64 & $96 \cdot 6$ & $(87-110)$ \\
\hline Laboratory supported definite & 22 & 5 & $7 \cdot 6$ & $(5-12)$ \\
\hline Clinically probable & 71 & 16 & $24 \cdot 4$ & $(19-31)$ \\
\hline Laboratory supported probable & 0 & 0 & $0 \cdot 0$ & $(0-0)$ \\
\hline Multiple sclerosis & 6 & 1 & $2 \cdot 1$ & $(2-6)$ \\
\hline Suspected & 61 & 14 & $21 \cdot 0$ & $(16-27)$ \\
\hline Total & 441 & 100 & $151 \cdot 7$ & $(138-167)$ \\
\hline \multicolumn{5}{|l|}{ Allison and Millar: } \\
\hline Probable & 347 & 79 & $119 \cdot 4$ & $(107-133)$ \\
\hline Possible & 94 & 21 & $32 \cdot 3$ & $(26-40)$ \\
\hline Total & 441 & 100 & $151 \cdot 7$ & $(138-167)$ \\
\hline
\end{tabular}

Multiple sclerosis - probable or definite multiple sclerosis, unverified.

practitioner records, and $3(1 \%)$ from the membership lists of the Multiple Sclerosis Society. No patients were notified solely from nursing homes or residential facilities for the disabled. Three hundred and twenty eight $(74 \%)$ of the 441 prevalent patients were interviewed; 70 $(16 \%)$ others either declined to take part or access was denied by their general practitioner; $8(2 \%)$ had died, and $35(8 \%)$ were too ill or failed to respond to serial requests for contact.

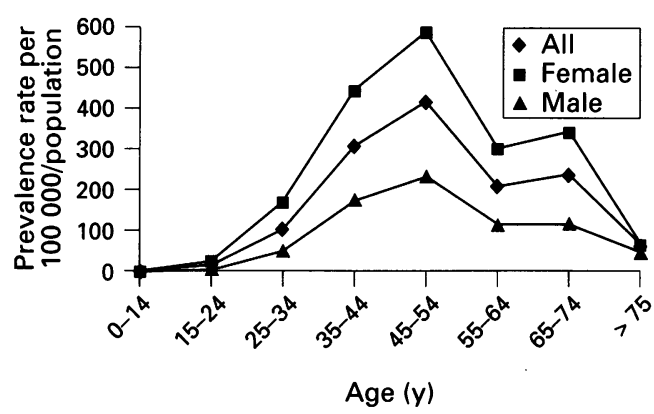

Figure 1 Age and sex specific prevalence of multiple sclerosis in south Cambridgeshire on fuly 11993.

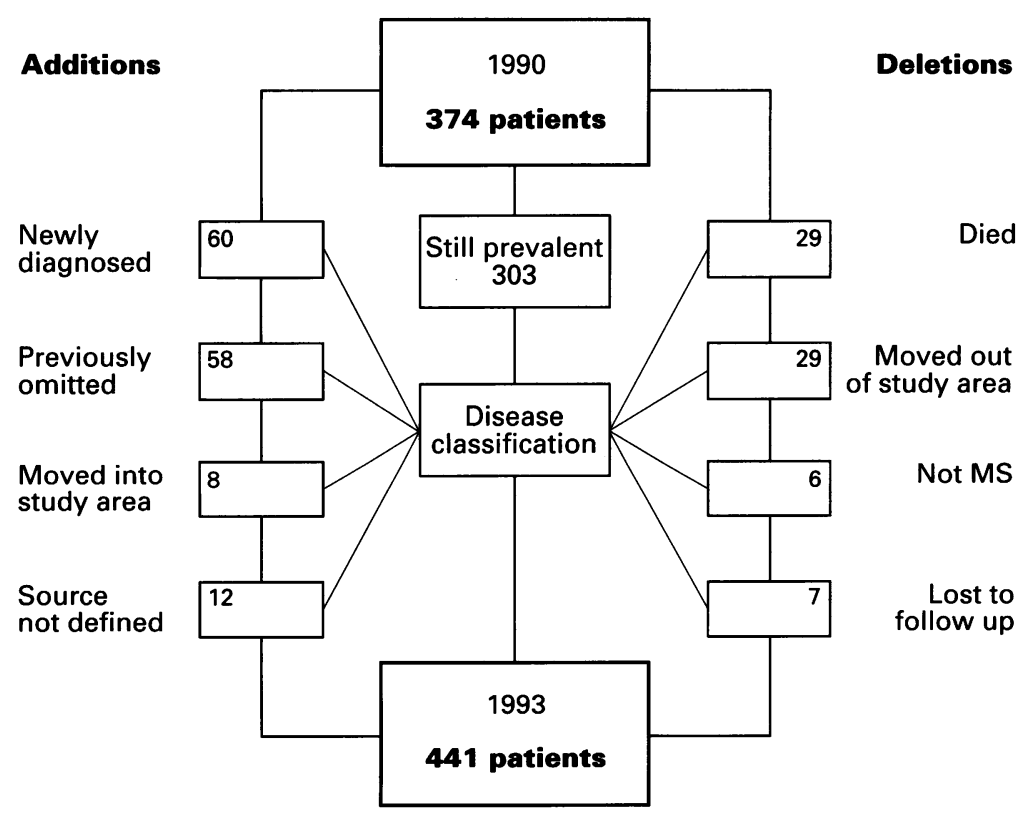

Total

138

71

Figure 2 Algorithm demonstrating the fate of the 374 patients prevalent in 1990 and the origin of the 138 newly recruited patients prevalent in 1993.
The diagnostic classification of the 441 prevalent patients is shown in table 1 . The prevalence of multiple sclerosis in south Cambridgeshire on the 1 July 1993 was $441 / 290700$ population $\left(152 / 10^{5} ; 95 \%\right.$ confidence interval (CI) 138,167$) ; 380\left(131 / 10^{5} ; 95 \%\right.$ CI 118 , 145) had either probable or definite disease and $61\left(21 / 10^{5} ; 95 \%\right.$ CI 16,27$)$ suspected disease. Figure 1 shows the age and sex specific prevalence of multiple sclerosis in the Cambridge Health District; this ranged from $12 / 10^{5}$ in the 15-24 years age group (males $4 / 10^{5}$, females $22 / 10^{5}$ ) to $410 / 10^{5}$ in the $45-54$ age group (males $236 / 10^{5}$, females $586 / 10^{5}$ ). The sex ratio was $2.6 \mathrm{~F}: \mathrm{M}$. The mean age of prevalent patients was 49 (range 18-85) years; the mean age at onset was 31.7 (range 10-61) years, and the mean age at diagnosis was 37.5 years. Mean disease duration was $17 \cdot 3$ years, from which a crude estimate of mean life expectancy of 34.6 years can be made by doubling disease duration, as first suggested by Poskanzer et al. ${ }^{13}$ Standardisation of prevalence to age and sex structure based on the 1961 census population of Northern Ireland demonstrated a standardised prevalence rate (SPR) of $179 / 10^{5}$ (95\%CI 164, 195).

Of the 374 patients registered in the original study, $303(81 \%)$ remained prevalent, $29(8 \%)$ had died, $29(8 \%)$ had moved out of the study area, and $6(1.6 \%)$ were considered not to have multiple sclerosis. All except one of these had previously been classified as having suspected disease; two had a functional illness, one had neurosarcoid, one focal cerebellar atrophy, one cerebrovascular disease, and one a thoracic spinal meningioma. Seven patients were untraceable. Thirty six (69\%) of the 52 patients originally classified as having suspected multiple sclerosis in the 1990 study remained in this diagnostic category; $11(21 \%)$ were reclassified as having probable or definite disease either because new neurological events had occurred or on the basis of investigations and/or information relating to previously documented clinical events the significance of which had not previously been appreciated. The conversion rate of possible multiple sclerosis to probable or definite diagnostic categories was estimated at $7 \%$ per year.

Twenty nine patients had died during 1990 93. The age at death ranged from $40-85$ years with a mean of 64.2 years. The mean disease duration in this cohort of patients, derived from historical or clinical records of the first neurological symptom considered unequivocally to be due to multiple sclerosis, was $28 \cdot 2$ years (range 11-38) - considerably less than the figure estimated for the entire prevalen population ( 34.6 years). The annual mortality rate for all prevalent cases was $3 \cdot 3 / 10^{5} /$ year.

The updated prevalence of $152 / 10^{5}$ (SPR $179 / 10^{5}$ ) represents an $18 \%$ increase over the figure obtained in 1990 . Of the 138 patients newly ascertained to the study, $8(6 \%)$ had recently moved into the study area; $58(42 \%)$ were living in the study area in 1990 and would have had enough clinical and/or historical evidence to have been registered at that time. In $12(9 \%)$ patients, the route of entry onto the 


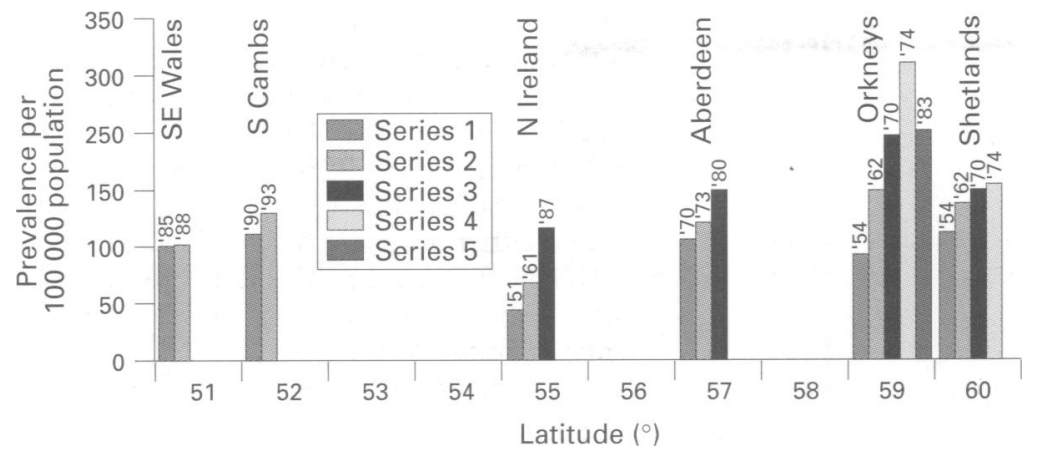

Figure 3 Serial prevalence studies of multiple sclerosis in the United Kingdom. All cases of multiple sclerosis based on Allison and Millar criteria except for SE Wales 1988 where information is available only for the Poser criteria.

register could not be clearly defined. In the period January 1990-December 1994, 269 new diagnoses of multiple sclerosis were made by Cambridge based neurologists, but $173(64 \%)$ patients did not live locally. Sixty patients lived in the study area and were prevalent on 1 July 1993. The mean incidence over the five year period was $6 \cdot 6 / 10^{5} /$ year for all disease classifications and $5 \cdot 0 / 10^{5} /$ year for definite and probable multiple sclerosis. Additions and deletions to the 1990 prevalence list are shown in figure 2 .

\section{Discussion}

The updated prevalence of multiple sclerosis in the south Cambridgeshire area was $152 / 10^{5}$. Apart from a small study of 62 patients in rural Suffolk in $1988,{ }^{14}$ which recorded a combined prevalence of $197 / 10^{5}$ for all disease classifications, this is the highest recorded figure for England and represents an $18 \%$ increase from 1990. It is significantly higher than prevalence data for two contemporary studies which also used the Poser disease classification and included all diagnostic categories in the southern United Kingdom - south Glamorgan $1985\left(117 / 10^{5} 95 \% \mathrm{CI} ; 107,129\right)^{12}$ and Southampton 1987 (99/10 $95 \%$ CI 89, 109). ${ }^{15}$ The survey from Sutton in $1985^{16}$ used the Allison and Millar diagnostic criteria, ${ }^{7}$ but reported a lower prevalence $\left(115 / 10^{5} ; 95 \%\right.$ CI 100,132$)$ than in Cambridge. Three more recent epidemiological studies are difficult to interpret since these are restricted to probable and definite multiple sclerosis only. For these disease categories, the three year follow up prevalence data for south Cambridgeshire remain significantly higher than Guernsey $\left(87 / 10^{5}\right.$; $95 \%$ CI 66,113$)^{17}$ and Mid-Downs (111/10 $95 \%$ CI 103,120$),{ }^{18}$ and also just reach significance for the small island population of Jersey $\left(113 / 10^{5} ; 95 \%\right.$ CI 92,138$) .{ }^{17}$

Higher rates of disease prevalence on second surveys are a well recognised but inconsistent phenomenon. Although they may result from increased incidence, the change is usually attributed to improved case ascertainment. The accurate prospective monitoring of a population with multiple sclerosis allows the relative contribution of each factor to be assessed. If the 58 previously unascertained patients had been included in the 1990 study, this would have increased the prevalence to $150 / 10^{5}$ at that time. Only a small component of the new figure can therefore be attributed to an increase in incidence over the same period. We therefore believe that the most recent figure represents more accurately the true prevalence rate in south Cambridgeshire.

The effects of population migration within the study area may also partly account for the observed increase in ascertainment. Twenty nine patients prevalent in $1990 \mathrm{had}$ left the area compared with eight who had moved in, representing a net emigration of 21 individuals. Population instability might be expected in an area where the major demographic centre is a university city. Temporary residents may remain registered with general practitioners outside the area, resulting in a time lag before local medical services become aware of their presence, particularly those with mild disease. Alternatively the disproportionately large cohort of young people may artificially inflate prevalence as a whole.

Prevalence is the product of incidence and disease duration and will alter with variation in either. Significant changes in incidence over time have been recorded in north east Scotland $^{2}$ and the Orkney ${ }^{19}$ and Shetland Islands, ${ }^{13}$ and these changes have been attributed to alterations in environmental exposure. However, the recorded incidence of disease may also be influenced by improved diagnostic facilities and techniques, and by local changes in clinical practice and diagnostic categorisation. These variations in methodology have plagued direct comparison of prevalence studies conducted at different times. The relationship of incidence to prevalence in a chronic disease such as multiple sclerosis is difficult to interpret without the benefit of long term studies of incidence which monitor temporal change, especially since disease duration and hence prevalence are influenced by treatments which improve management of disease complications.

Studies of incidence and mortality are likely to be the most reliable method of predicting future epidemiological patterns of disease. These provide evidence for changes in aetiological risk factors with time and are useful in planning the distribution of health care resources. It is also important to know the true prevalence for the study area, assuming stable incidence, disease duration, and population structure. Since the mean duration of disease in our population calculated from prevalence and mortality data is 28.2 years, the estimated prevalence is $186 / 10^{5}$. The 1990 study yielded $70 \%\left(130 / 10^{5}\right)$ and this has increased in the most recent survey to $82 \%\left(152 / 10^{5}\right)$. An estimated $18 \%$ therefore remain to be ascertained; clearly some individuals have only trivial manifestations of disease and are yet to present to a physician. Concerns about confidentiality and reluctance to notify patients with suspected and mild disease will also contribute to incomplete ascertainment. Patients who tend to be overlooked also include those moving in and out of areas where population dynamics are poorly documented. Our figures 
Table 2 Contemporary United Kingdom incidence data for multiple sclerosis

\begin{tabular}{|c|c|c|c|c|c|c|c|c|c|}
\hline Study & $\begin{array}{l}\text { Disease } \\
\text { classification }\end{array}$ & Population & Interval & No & Incidence & Mortality & Duration & $\begin{array}{l}\text { Prevalence } \\
\text { observed }\end{array}$ & $\begin{array}{l}\text { Prevalence } \\
\text { estimated }\end{array}$ \\
\hline \multicolumn{10}{|l|}{ Prospective: } \\
\hline Aberdeen & $A+M$ & 440200 & $1959-80$ & $647^{*}$ & $7 \cdot 0$ & $5 \cdot 0$ & $24 \cdot 5$ & 178 & 172 \\
\hline Okneys & $A+M$ & 19082 & $1954-74$ & 66 & $9 \cdot 3$ & $1 \cdot 7$ & $22 \cdot 0$ & 240 & 205 \\
\hline Shetlands & $A+M$ & 18587 & $1954-74$ & 53 & $7 \cdot 5$ & $1 \cdot 4$ & $27 \cdot 0$ & 184 & 203 \\
\hline SE Wales & Poser & 389000 & $1985-88$ & 61 & $8 \cdot 2$ & $3 \cdot 4$ & $21 \cdot 7$ & 120 & 178 \\
\hline S Cambs & Poser & 290700 & $1990-95$ & 96 & $6 \cdot \overline{6}$ & $3 \cdot 3$ & $28 \cdot 2$ & 152 & 186 \\
\hline \multicolumn{10}{|l|}{ Retrospective: } \\
\hline N Ireland & $A+M$ & 1425000 & $1948-68$ & - & $4 \cdot 8$ & $3 \cdot 1$ & $32 \cdot 0^{*}$ & 80 & 154 \\
\hline Sutton & $\mathrm{A}+\mathrm{M}$ & 169600 & $1976-84$ & 77 & $5 \cdot 0$ & - & $30 \cdot 8^{*}$ & 119 & 154 \\
\hline Southampton & Poser & 417000 & $1976-82$ & 129 & $4 \cdot 7$ & - & $31 \cdot 4^{*}$ & 99 & 148 \\
\hline Sussex & Poser & 596594 & $1978-84$ & 195 & $5 \cdot 0$ & - & $31 \cdot 0^{*}$ & 111 & 155 \\
\hline
\end{tabular}

* Derived from incidence data. $\mathrm{A}+\mathrm{M}=$ Allison and Millar classification.

demonstrate that even carefully performed studies on previously unsurveyed populations may significantly underestimate prevalence.

It is difficult to say what role these factors may have played in other geographical areas that have been subject to serial studies, but it is of interest that although the most recently reported prevalence from north east Scotland was $178 / 10^{5},{ }^{2}$ the statistics for 1970 and 1973 were $127 / 10^{5}$ and $144 / 10^{5}$ respectively. ${ }^{78}$ These closely relate to the three year increase seen in south Cambridgeshire and also to the estimated maximum prevalence. Analysis of serial studies within the United Kingdom demonstrates an increase in prevalence for all second, third, and fourth studies irrespective of latitude (fig 3). A fifth study of the Orkney Islands demonstrates a small fall in prevalence from 309/105 in 1974 to $240 / 105$ in $1983,{ }^{9}$ but whether this represents a true fall in incidence or reflects saturation of ascertainment from repeated survey is unclear. However, these areas also demonstrate equivalent effects of increased case ascertainment on second surveys, although the effect is less marked in subsequent studies. In north east Scotland, $50(8 \%)$ patients who would have been prevalent in $1970^{8}$ were identified in 1973 and $18(2 \%)$ who would have been prevalent in 1973 were identified in $1980 .{ }^{20}$ In the Orkney and Shetland Islands respectively, $26(153 \%)$ and $14(64 \%)$ patients were identified in 1974 who had a disease onset prior to the first study in 1954 and were only identified after three further studies. ${ }^{13}$ There were $6(1 \%)$ patients in south east Wales in $1988^{1}$ who would have been prevalent in 1985 . No equivalent data are available for Northern Ireland.

Over the years there has been considerable variation in regional incidence figures within the United Kingdom - from $12 \cdot 0 / 10^{5}$ in the Orkneys between 1940 and $1944^{13}$ to $2 \cdot 4 / 10^{5}$ in Stamford, Lincolnshire in $1949 .{ }^{21}$ Direct methodological comparison is difficult since diagnostic classifications in earlier studies differ, although providing all categories of disease are considered it makes little difference to total numbers. ${ }^{22}$ It is also likely that neurological services have been better staffed in recent years (Cambridge has four neurologists compared with only one in Aberdeen at the inception of its register). Furthermore, it is not possible to produce incidence data standardised for age and sex from available population data and differences in population age and sex structures over time may make a substantial impact on comparability and the validity of conclusions reached. However, prospective incidence registers are still likely to provide the most accurate figures for the underlying frequency in a defined area.

In table 2 we have listed data for contemporary incidence figures within the United Kingdom and estimated prevalence from disease duration. Two classes of information exist; firstly, the more robust one derived from prospective registers recorded by neurologists working from a regional centre or, in the case of the Orkney and Shetlands, by the chief medical officer, and secondly, data derived from retrospective age of onset information collected in cross sectional studies, which have uniformly employed multiple ascertainment sources similar to this study. The similarities of recent estimates for incidence and prevalence irrespective of latitude and despite persistent differences in observed prevalence, suggest that there is more uniform distribution of multiple sclerosis than has hitherto been assumed.

Clearly the claim for a latitudinal gradient of disease does not rely entirely on the observations of disease frequency within the United Kingdom, but these do have particular importance since the claim for a steep gradien was responsible for generating many early hypotheses on the pathogenesis of multiple sclerosis. Latitudinal gradients have also been recorded within New Zealand, ${ }^{23}$ Australia, ${ }^{24}$ and North America, ${ }^{25}$ although it is relevant that earlier analyses may have failed to incorporate the impact of race on geographical distribution. ${ }^{26}$ In Europe, evidence for a disease gradient was based primarily on serial studies from the United Kingdom and those carried out in Italy between 1959 and 1975 reporting prevalences varying between 5 and $25 / 10^{5}$. More recent studies from Italy and other southern European countries, based on improved case ascertainment and consistent diagnostic classification, suggest that prevalence in these areas is higher than was first appreciated, ${ }^{27}$ and examination of incidence data alone in the 1980s within Europe has the effect of removing the direct relationship to latitude. ${ }^{28}$

Taken as a whole these observations bring into question the presence of a direct relationship between disease frequency and latitude within the United Kingdom, where the disease gradient has until recently been considered to be the steepest in the world. 
1 Hennessy A, Swingler RJ, Compston DAS. The incidence and mortality of multiple sclerosis in south east Wales. $\mathcal{F}$ Neurl Neurosurg Psychiatry 1989;52:1085-9.

2 Phadke JG, Downie AW. Epidemiology of multiple sclerosis in north east (Grampian Region) of Scotland. $\tilde{f}$ Epidemiol Community Health 1987;41:5-13.

3 Allison RS. Some neurologic aspects of medical geography. Proc Roy Soc Med 1963;56:71-6.

4 Mumford CJ, Fraser MB, Wood NW, Compston DAS. Multiple sclerosis in the Cambridge Health Authority. $\mathcal{f}$ Neurol Neurosurg Psychiatry 1992;55:877-82.

5 Cambridgeshire County Council Research Group. Population forecasts 1989-2001. Cambridge: Cambridgeshire County Council, 1992.

6 Poser C, Paty D, Scheinberg L, et al. New diagnostic criteria for multiple sclerosis: guidelines for research protocols. Ann Neurol 1983;13:227-31.

7 Allison RS, Millar JHD. Prevalence and familial incidence of disseminated sclerosis (A report to the Northern Ireland of disseminated sclerosis (A report to the Northern Ireland Ulster Med $\mathcal{f} 1954 ; 23: 5-27$.

8 Shepherd DI, Downie AW. Prevalence of multiple sclerosis in north-east Scotland. $B M \mathcal{F}$ 1978;ii:314-16.

9 Shepherd DI, Downie AW. A further prevalence study of multiple. sclerosis in north-east Scotland. $\mathcal{F}$ Neurol Neurosurg Psychiatry 1980;43:310-15.

10 Downie AW, Phadke JG. The Chief Scientist reports ... multiple sclerosis in north east Scotland. Health Bulletin (Edin) 1983;42:151-6.

11 Millar JHD. Multiple sclerosis in Northern Ireland. In: Clifford Rose F, ed. Clinical neuroepidemiology. Tunbridg Wells: Pitman Medical, 1980: 222-7.

12 Swingler RJ, Compston DAS. The prevalence of multiple sclerosis in south east Wales. F Neurol Neurosurg Psychiatry 1988;51:1520-2524.

13 Poskanzer DC, Prenny LB, Sheridan JL, Condy JW. Multiple sclerosis in the Orkney and Shetland Islands. 1: Epidemiology, clinical factors and methodology. $f \mathrm{Ep}$ idemiol Community Health 1980;34:229-39.

14 Lockyer M. Prevalence of multiple sclerosis in five rural Suffolk practices. BMF 1981;303:347-8.
15 Roberts MHW, Martin JP, McLellan DL, McIntosh-Michaelis SA, Spackman AJ. The prevalence of multiple.sclerosis in the Southampton and South West Hampshire Health Authority. $₹$ Neurl Neurosurg Psychiatry 1990;53:55-9.

16 Williams ES, McKeran RO. Prevalence of multiple sclerosis in a south London borough. BMf 1978;293:237-9.

17 Sharpe G, Price SE, Last A, Thompson RJ. Multiple sclerosis in island population - prevalence in the Bailiwicks of
s. Price SE, Last A, Thompson RJ. Multiple scleroGuernsey and Jersey. F Neurol Neurosurg Psychiatry 1995; 58:22-6.

18 Rice-Oxley M, Williams ES, Rees JR. A prevalent survey of multiple sclerosis in Sussex. $\mathcal{f}$ Neurol Neurosurg Psychiatry 1995;58:27-30.

19 Cook SE, Cromerty JI. Declining incidence of multiple sclerosis in the Orkney Islands. Neumlogy 1985;35:545-51.

20 Phadke JG, Downie AW. Epidemiology of multiple sclerosis in north-east (Grampian Region) of Scotland 7 Epidemiol Community Health 1987;41:5-13.

21 Swingler RI, Compston DAS. The distribution of multiple sclerosis in the United Kingdom. $\mathcal{f}$ Neurol Neurosurg Psychiatry 1986;49:1115-24.

22 Robertson NP, Compston DAS. Surveying multiple sclerosis in the United Kingdom. $\mathcal{F}$ Neurol Neurosurg Psychiatry 1995;58:2-6.

23 Skegg CG, Corwin PA, Craven RS, Malloch JA, Pollack M. Occurrence of multiple sclerosis in the north and south of New Zealand. $\mathcal{f}$ Neurol Neurosurg Psychiatry 1987;50: $134-9$.

24 Hammond SR, McLeod JG, Millingen KS, et al. The epidemiology of multiple sclerosis in three Australian cities: Perth, Newcastle and Hobart. Brain 1987;111:1-25.

25 Kurtzke JF, Beebe GW, Norman JJE. Epidemiology of multiple sclerosis in U.S. veterans. 1. Race, sex and geomultiple sclerosis in U.S. veterans. 1. Race, sex and

26 Bulman D, Ebers GC. The geography of multiple sclerosis reflects genetic susceptibility. J Trop Geogr Neurol 1992; reflects genc.

27 Rosati G, Aiello I, Pirastru M, et al. Prevalence and incidence study of multiple sclerosis in the district of Tempio, Sardinia, 1960 to 1986. Ital $\mathcal{F}$ Neuml Sci 1991;12(suppl 5):28a.

28 Rosati G. Descriptive epidemiology of multiple sclerosis in Europe in the 1980s: A critical overview. Ann Neurol 1994; 36(suppl 2):S164-74. 